\title{
Heat Transfer Enhancement in a Circular Pipe using Rotary Twisted Tape Inserts
}

\author{
Shyam S. Darewar ${ }^{*}$, Vinayak M. Kale ${ }^{\ddagger}$ \\ †Department of Mechanical Engineering, Pune University, PES Modern College of Engineering, Pune, India \\ ‡Department of Mechanical Engineering, Pune University, Indira College of Engineering and Management, Pune, India
}

Accepted 15 June 2016, Available online 20 June 2016, Special Issue-5 (June 2016)

\begin{abstract}
The present experimentation is on rotary twisted tape insert with a three different twist ratio $y=3.0,4.0$ and 5.0. The Reynolds number used is in the range of 35000 to 45000. The effect of rotary twisted tape on heat transfer enhancement and pressure drop has been studied. The twisted tape inserts develops a strong swirl flow within fluid flow which increases heat transfer rate. A constant heat flux condition was used for experimentation. The experimental results shows that the maximum heat transfer coefficient of fixed twisted tape insert is 1.55 times the pipe without insert at $y=3.0$ and Reynolds number 45000 and when we compare these results with rotary twisted tape inserts the maximum heat transfer coefficient obtained is 1.98 times the smooth pipe for $y=3.0$ and at the speed of 150RPM. The pressure drop occurred is 4.14 times at $y=3.0,3.85$ at $y=4.0$ and 3.42 at $y=5.0$ with respect to plain tube but these values does not changes significantly with the rotary twisted tape inserts at various RPM.
\end{abstract}

Keywords: Heat transfer coefficient, Rotary twisted tape inserts, Nusselt number Ratio, pressure drop, swirl flow.

\section{Introduction}

Heat exchanger is a widely used industrial device. Many researchers have investigated the different techniques to improve performance of the heat exchanger;

- To increase the heat transfer efficiency of heat exchanger

- To reduce the size of the heat exchanger.

- To reduce the cost of manufacturing by reducing material cost.

- To make it compact to reduce floor space area required for the heat exchanger.

- To effective utilization of the fuel.

These techniques are known as heat augmentation techniques and are classified as;

- Active technique

- Passive technique

Active techniques requires external power source for its operation while in passive technique it doesn't required any external power source.

Twisted tape insert is one of the swirl generator belongs to the passive technique of heat augmentation. Among different passive means used to increase heat transfer coefficient, twisted tape inserts are excellent. The twisted tape creates the swirl flow within the pipe

*Corresponding author: Shyam S. Darewar which ensures greater mixing of the flow. The turbulent flow continuously changes the boundary layer thickness and form new boundary layer. This result in improved thermal contact of the fluid with tube thereby increasing heat transfer rate. The twisted tape inserts have continuous change in its geometry due to the helical twists which result in high turbulence inside the pipe which increases heat transfer coefficient significantly. The twisted tapes are very simple for manufacturing and can be inserted easily inside the pipe of heat exchanger. Due to the insertion of the twisted tape as turbulence in the pipe increases the pressure drop is also increases which result in higher pumping power requirement. So it is necessary to find the best possible method of improving heat transfer rate with minimum pressure drop penalty.

Many researchers have studied the effect of different geometries of twisted tape on heat transfer enhancement and pressure drop. Few of them are as follows;

(Marner, et al April-2012) were the first investigators to recognize the importance of uniform wall temperature (UWT) boundary condition to a major group of heat exchanger used in chemical industry. They studied UWT heating and cooling of ethylene glycol $(\mathrm{Pr}=24-85, \mathrm{Re}=3803470)$ using single twisted tape insert of $y=5.4$ in a tube and internally finned tubes, and observed that both heat transfer and friction factor increased substantially beyond 
particular Reynolds number, at which secondary swirl flow and turbulence were induced in the flowing fluid. (Anil Singh Yadav March. 2009) studied Influences of the half length twisted tape insertion on heat transfer and pressure drop characteristics in U-bend double pipe heat exchanger. The experimental results revealed that the increase in heat transfer rate of the twistedtape inserts is found to be strongly influenced by tapeinduced swirl or vortex motion. The heat transfer coefficient is found to increase by $40 \%$ with half-length twisted tape inserts when compared with plain heat exchanger. It was found that on the basis of equal mass flow rate, the heat transfer performance of half-length twisted tape is better than plain heat exchanger, and on the basis of unit pressure drop the heat transfer performance of smooth tube is better than half-length twisted tape. It is also observed that the thermal performance of Plain heat exchanger is better than half length twisted tape by 1.3-1.5 times.

(P. Eiamsa-ard, et al 2014) studied Effects of the regularly-spaced twisted tape (RS-TT) on the heat transfer, friction factor and thermal performance factor behaviours in a heat exchanger are reported along with those of a full length twisted tape. The full length (or typical) twisted tapes with two different twist ratios $(y=P / W=6.0$ and 8.0), and the regularly-spaced twisted tape (RS-TT) with two different twist ratios $(\mathrm{y}=6.0$ and 8.0) and three free space ratios $(\mathrm{s}=\mathrm{S} / \mathrm{P}=1.0,2.0$, and 3.0) were employed for comparative study. The experimental results show that heat transfer rate and friction increased with decreasing twist ratio and space ratio. At similar conditions, full length twisted tapes (s $=0$ ) offered higher heat transfer rate, friction factor and thermal performance factor than RS-TT ones ( $s=1.0$, 2.0 and 3.0) as they induced more consistent swirling flows and thus turbulence. This reveals that it is possible to gain promising tradeoff between enhanced heat transfer and increased friction by selecting the twisted tape with proper geometries.

(Bodius, Salam et al 2013) did the experimental investigation for measuring tube-side heat transfer coefficient, friction factor, heat transfer enhancement efficiency of water for turbulent flow in a circular tube fitted with rectangular-cut twisted tape insert. A copper tube of $26.6 \mathrm{~mm}$ internal diameter and $30 \mathrm{~mm}$ outer diameter and $900 \mathrm{~mm}$ test length was used. A stainless steel rectangular-cut twisted tape insert of 5.25 twist ratio was inserted into the smooth tube. The rectangular cut had $8 \mathrm{~mm}$ depth and $14 \mathrm{~mm}$ width. A uniform heat flux condition was created by wrapping nichrome wire around the test section and fiber glass over the wire. At comparable Reynolds number, Nusselt numbers in tube with rectangular-cut twisted tape insert were enhanced by 2.3 to 2.9 times at the cost of increase of friction factors by 1.4 to 1.8 times compared to that of smooth tube. Heat transfer enhancement efficiencies were found to be in the range of 1.9 to 2.3 and increased with the increase of Reynolds number.
(P. Murugesan, et al Dec. 2011) performed Experimental investigation of heat transfer and friction factor characteristics of circular tube fitted with plain twisted tapes (PTT) and U-cut twisted tapes (UTT) with twist ratios $y=2.0,4.4$ and 6.0. The Nusselt number and friction factor values for the tube with UTT are noticeably higher than that of plain tube and also tube equipped with PTT. Over the range of Reynolds number considered average thermal enhancement factors in the tube equipped with PTT are found 1.15, 1.06, and 1.02 and tube equipped with UTT are 1.22, 1.10 and 1.06 respectively for twist ratios $\mathrm{y}=2.0,4.4$ and 6.0 . The thermal enhancement factors for all the cases are more than unity indicates that the effect of heat transfer enhancement due to the enhancing tool is more dominant than the effect of rising friction factor and vice versa.

(M.M.K. Bhuiya, et al 2013) investigate, the influence of triple twisted tapes on heat transfer rate, friction factor and thermal enhancement efficiency The investigations were conducted using the mild steel triple twisted tapes with four different twist ratios $(\mathrm{y}=$ $1.92,2.88,4.81$ and 6.79) for Reynolds number ranging from 7200 to 50,200 under uniform heat flux condition. The results indicated that the presence of triple twisted tapes led to a higher increase in the heat transfer rate over the plain tube. The Nusselt number and friction factor of using the triple twisted tape inserts were found to be increased up to 3.85 and 4.2 times when compared with the plain tube, respectively. The heat transfer performance was evaluated based on the constant blower power and the performance was achieved to be 1.44 by the use of triple twisted tape inserts.

\section{Experimental Set Up}

Fig. 1 shows the experimental set up of the present experimentation. A copper pipe of inside diameter $\mathrm{ID}=35.1 \mathrm{~mm}$, outside diameter $\mathrm{OD}=38.1 \mathrm{~mm}$ and length $900 \mathrm{~mm}$ was used for the experimentation. The pipe length of $800 \mathrm{~mm}$ was considered as test section. . Pressure tapping was provided at the distance of $860 \mathrm{~mm}$. A nichrome wire of gauge 30 and resistance $0.15 \Omega / \mathrm{cm}$ was spirally wound over the test pipe. A porcelain beads were used on nichrome wire to make the test section electrically insulated. An asbestos rope was wound over nichrome wire to avoid any heat losses to the surrounding. An aluminium twisted tape of width $\mathrm{w}=20 \mathrm{~mm}$, thickness $\mathrm{t}=1.5 \mathrm{~mm}$ and length $800 \mathrm{~mm}$ was inserted inside the test pipe. The twisted tapes with three different twist ratios of $(y=p / w=3.0$, 4.0 and 5.0 was used for experimentation. The twisted tapes were supported in the bearings located at the two ends. The twisted tapes were made rotated at the speed of 50RPM to 150 RPM. A blower of $450 \mathrm{~W}$ and air capacity of $1.6 \mathrm{~m}^{3} / \mathrm{sec}$ was used for the experimentation. A ball valve was used to control the flow rate of the air according to the need of experimentation. J-type thermocouples were used for measuring the temperatures at the different point on 
the pipe. Six thermocouples were fixed over the surface of the pipe to measure surface temperature while two thermocouples were inserted inside the pipe to measure inlet and outlet temperature of the air. A voltmeter and ammeter were used to measure the voltage and current in the nichrome wire. A $10 \mathrm{~A}$ dimmer stat of the range $260 \mathrm{~V}$ was used to maintain constant heat flux condition.

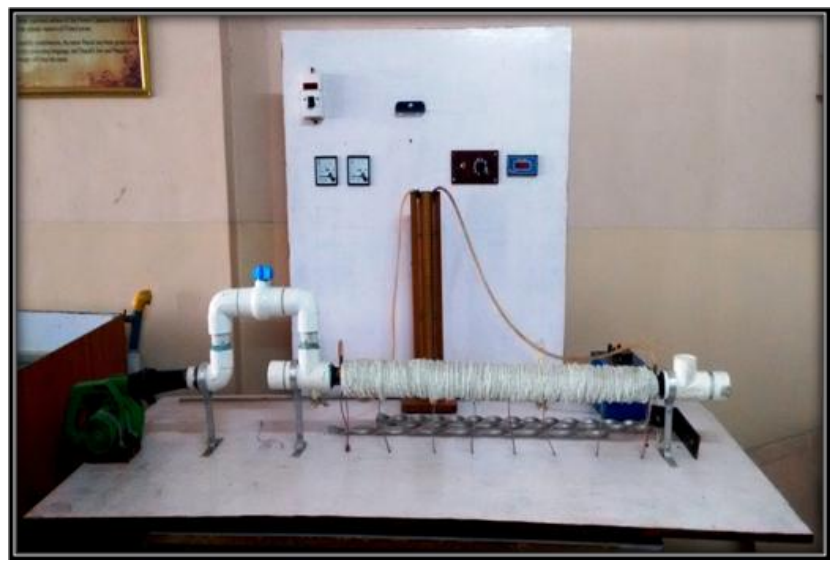

Fig. 1 Actual Experimental set up

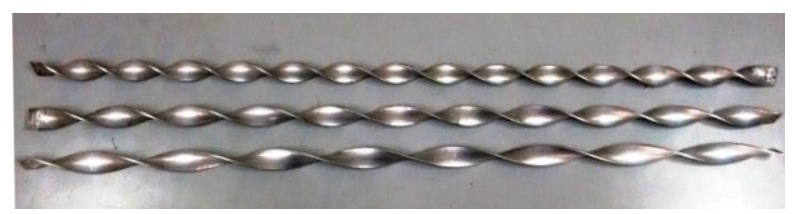

Fig. 2 Twisted Tape Inserts of $y=3.0,4.0,5.0$

\subsection{Experimental Procedure}

The experiment was performed in three steps;

- The first step consists of investigation of the heat transfer characteristics without using the insert.

- The second step was consists of investigation of heat transfer characteristics using a typical fixed twisted tape inserts.

- The third step was consists of investigation of heat transfer characteristics using rotary twisted tape insert.

The experimentation was started with rising the temperature of the test section with the help of Dimmer stat. The dimmer stat maintains constant heat flux condition by supplying uniform voltage across the nichrome wire. A $450 \mathrm{~W}$ blower has started to circulate the air at room temperature through the pipe. The flow rate of the air was set by using a flow control valve. The velocity was measured with the help of vane type anemometer which helps to obtain required Reynolds number according to the experimentation. After some time, the temperature was reached a steady state condition. The temperatures were displayed on temperature indicator by the respective thermocouple at the outer surface of the pipe test section to determine the average surface temperatures. Two separate thermocouples were inserted at the inlet and outlet housing for determining the air inlet and outlet temperature.

When the temperature was not changed for 1-2 minutes, then readings were taken. The manometer reading was recorded for measuring pressure drop across the pipe. The above experimental procedure was repeated for different Reynolds number and twist ratios for fixed twisted tape inserts and rotary twisted tape inserts with different speed (50 to 150RPM). The results obtained from the experimentation were used for calculating the heat transfer coefficient, and pressure drop and thermal performance factor. All the results from above three steps were compared to each other to find best possible method of improving heat transfer rate.

\subsection{Calculation Methodology}

The heat added by the heater was calculated by the heat added to the Air. Heat added to the air is calculated by,

$$
Q=\dot{m} c_{p}\left(T_{o}-T_{i}\right)
$$

Where, $m$ is mass flow rate of air, $C p$ specific heat capacity of air and $\Delta T$ is difference between inlet and outlet temperature.

Heat transfer coefficient was calculated from,

$$
h=\frac{q^{\prime \prime}}{A\left(T_{w i}-T_{b}\right)}
$$

Where $q^{\prime \prime}$ is the heat flux, $T_{w i}$ average inner surface temperature and $T_{b}$ is the bulk temperature.

Bulk temperature is given by;

$$
T_{b}=\frac{T_{i}+T_{o}}{2}
$$

Tube outer surface temperature was calculated from the average of six local tube outer surface temperatures,

$$
T_{w o}=\sum_{i=1}^{n=6} \frac{T_{w o, i}}{6}
$$

Where $T_{w o}$ the average is outer surface temperature and $T_{w o, i}$ is the local outer surface temperature.

Tube inner surface temperatures were calculated from one dimensional radial conduction equation,

$$
T_{w i}=T_{w o}-Q \cdot \frac{\ln \frac{d_{o}}{d_{i}}}{2 \pi k_{w} L}
$$

Where $T_{w i}=$ outer surface temperature, $T_{w o}=$ average outer surface temperature, $\mathrm{Q}$ is the heat added to Air, $d_{o}$ is the outer diameter of pipe, $d_{i}$ is the inner diameter of pipe, $K_{w}$ is the thermal conductivity of copper pipe and $L$ is the length of test section.

Reynolds number was calculated from;

$$
R e=\frac{4 m}{\pi d_{i} \mu}
$$


Where $m$ the mass flow rate of Air, $d_{i}$ is the inner diameter of pipe and $\mu$ is the dynamic viscosity of Air at a particular bulk temperature.

Nusselt number was calculated from,

$$
N u=\frac{h d_{i}}{k}
$$

Where $h$ the heat transfer coefficient, $d_{i}$ is the inner diameter of pipe, and $k$ is the thermal conductivity of the Air at corresponding bulk temperature.

Friction Factor was given by,

$$
f=\frac{\Delta P}{\left(\frac{L}{D}\right)\left(\rho V^{2} / 2\right)}
$$

Thermal performance factor was calculated from,

$$
\eta=\left|\frac{N u}{N u_{s}}\right|
$$

Where $h_{s}$ is the heat transfer coefficient of smooth pipe configuration and $h_{e}$ is the heat transfer coefficient of the pipe flow using rotating twisted tape insert.

\section{Result and Discussion}

In this experimentation the twisted tape inserts were made rotated to find its effect on heat transfer coefficient and pressure drop characteristics. The results obtained from the experimentation with rotary twisted tape were compared with the typical fixed twisted tape inserts and the smooth pipe without inserts.

\subsection{Heat Transfer Coefficient (h)}

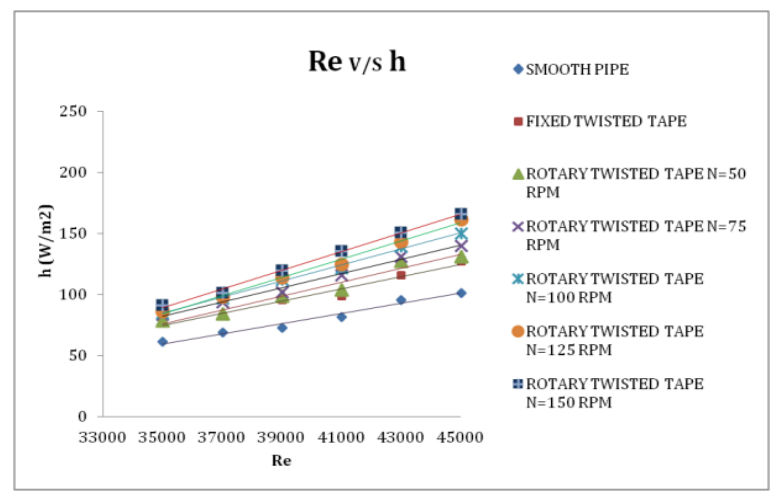

Fig. 3 Re V/S h for Fixed and Rotary Twisted Tape at $y=3.0$ and Its Comparison with Smooth Pipe

From the fig. 3, $4 \& 5$ it is found that the heat transfer coefficient for the fixed twisted tape insert is increases around 1.55 times at $y=3.0,1.25$ times at $y=4.0$ and 1.17 times at $y=5.0$ compared to the smooth pipe without inserts while the results of rotary twisted tape reveals that the heat transfer coefficient increases with the values of 1.82 to 2.03 times at $y=3.0,1.35$ to 1.65 times at $\mathrm{y}=4.0$ and 1.29 to 1.58 times at $\mathrm{y}=5.0$ as compared to the smooth pipe without inserts when speed increases from 50 RPM to 150 RPM. These results shows that at smaller twist ratio and at the higher Reynolds number the twisted tape insert gives maximum heat transfer coefficient.

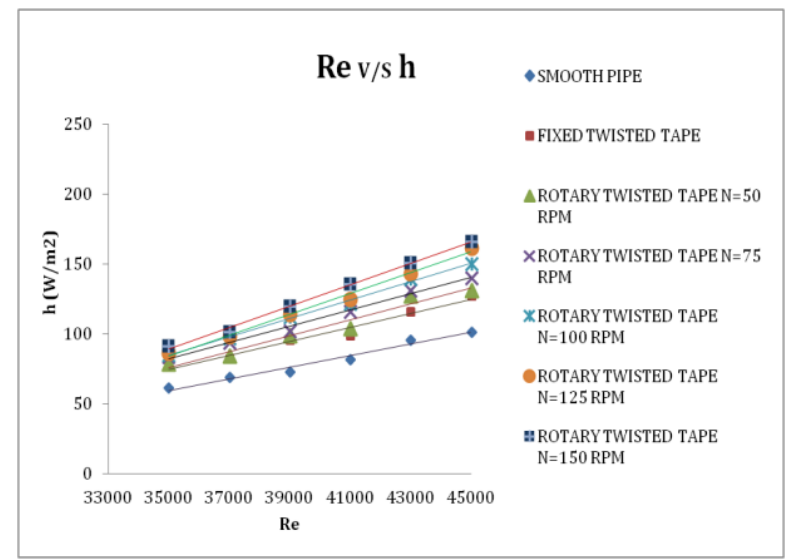

Fig. $4 \mathrm{Re} V / \mathrm{S}$ h for Fixed and Rotary Twisted Tape at $\mathrm{y}=4.0$ and Its Comparison with Smooth Pipe

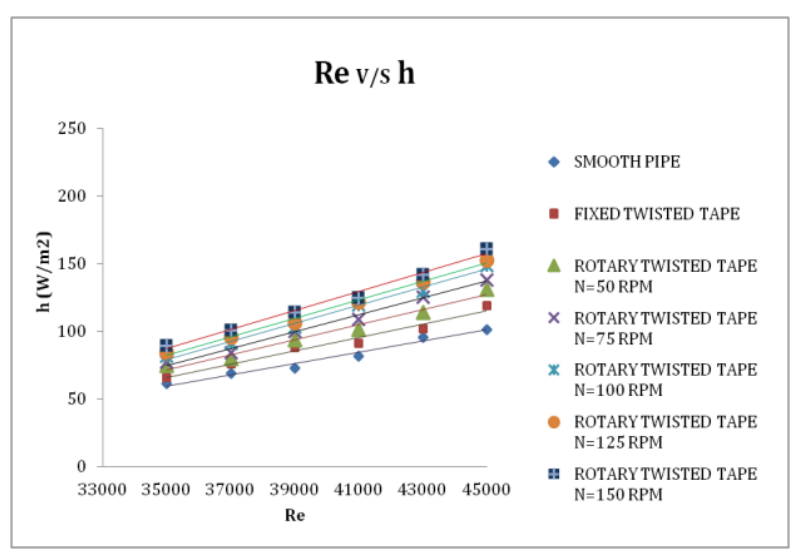

Fig. $5 \mathrm{Re} \mathrm{V/S} \mathrm{h}$ for Fixed and Rotary Twisted Tape at $\mathrm{y}=5.0$ and Its Comparison with Smooth Pipe

\subsection{Thermal Performance Factor $\mathrm{Nu} / \mathrm{Nu}_{\mathrm{s}}$}

This experimentation is the comparative study of effect of fixed and rotary twisted tape inserts on hear transfer rate of the heat exchanger.

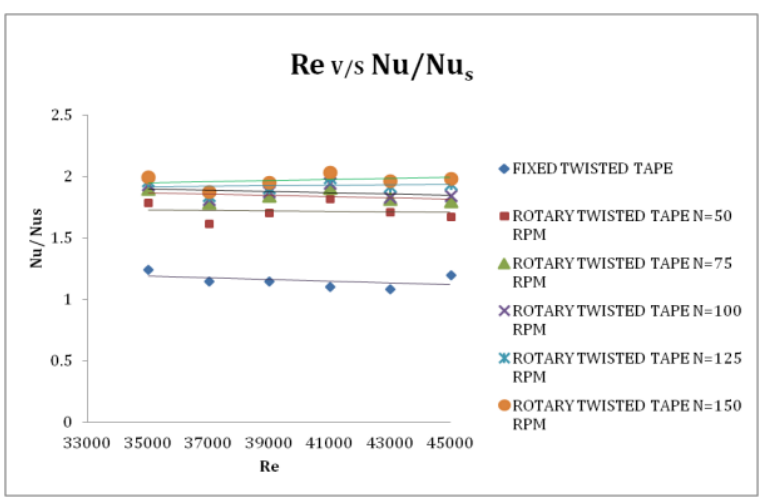

Fig. $6 \mathrm{Re} \mathrm{V/S} \mathrm{Nu} / \mathrm{Nu}_{\mathrm{s}}$ for fixed and rotary twisted tape inserts at $\mathrm{y}=3.0$ 


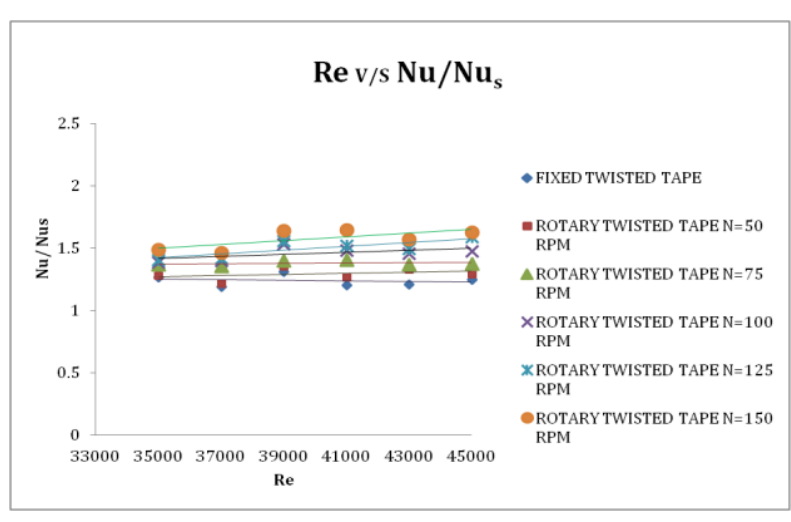

Fig. $7 \mathrm{Re} \mathrm{V/S} \mathrm{Nu/Nu}$ for fixed and rotary twisted tape inserts at $\mathrm{y}=4.0$

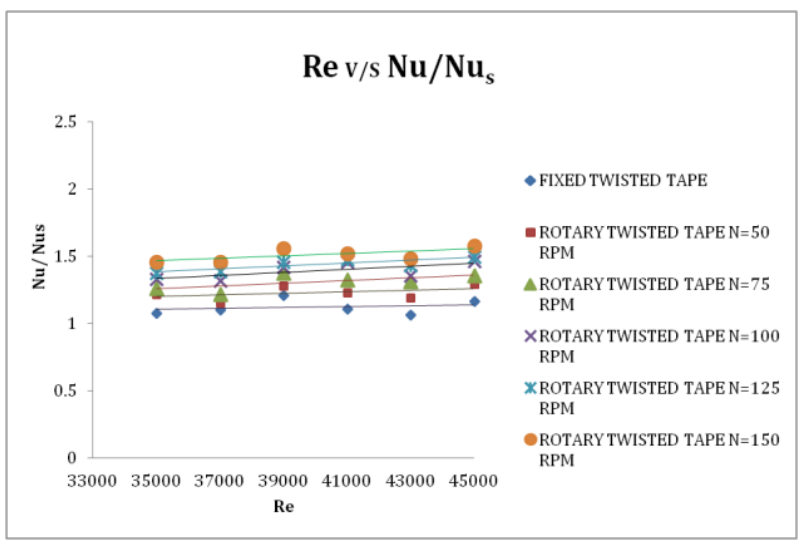

Fig. $8 \mathrm{Re} \mathrm{V} / \mathrm{S} \mathrm{Nu} / \mathrm{Nu}_{\mathrm{s}}$ for fixed and rotary twisted tape inserts at $\mathrm{y}=5.0$

The fig. $6,7 \& 8$ shows that the thermal performance factor of heat exchanger increases about 1.63 times at $\mathrm{y}=3.0,1.31$ times at $\mathrm{y}=4.0$ and 1.20 times at $\mathrm{y}=5.0$ compared to plain tube without insert and these values increases from 1.82 to 2.02 times at $y=3.0,1.35$ to 1.65 times at $\mathrm{y}=4.0$ and 1.28 to 1.58 times at $\mathrm{y}=5.0$ for rotary twisted tape inserts with increasing speed from 50RPM to 150RPM and Reynolds number

\subsection{Pressure Drop $(\Delta P)$}

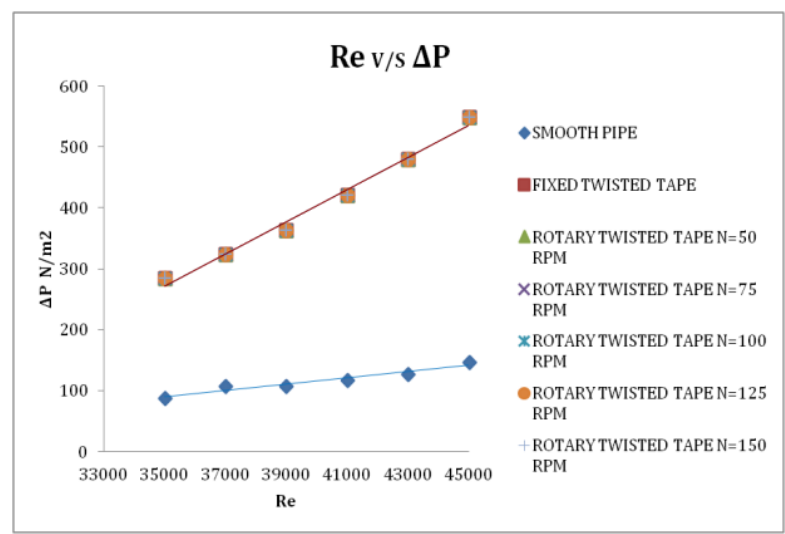

Fig. $9 \operatorname{Re} V / S \Delta P$ for fixed twisted tape for $y=3.0$ and its comparison with smooth pipe
The twisted tape inserts develops the strong swirl flow within the fluid flow which increases the pressure drop within the heat exchanger. In the present experimentation the comparative effect of fixed twisted tape insert and rotary twisted tape insert on pressure drop was studied. From the fig. 9, 10 \& 11 The experimental results shows that the fixed twisted tape inserts increases pressure drop in a pipe around 4.14 times at $\mathrm{y}=3.0,3.85$ at $\mathrm{y}=4.0$ and 3.42 at $\mathrm{y}=5.0$ with respect to plain tube while these values does not changes significantly for the rotary twisted tape inserts at different from 50 to 150RPM. These values also show that the pressure drop increases with decreasing twist ratios.

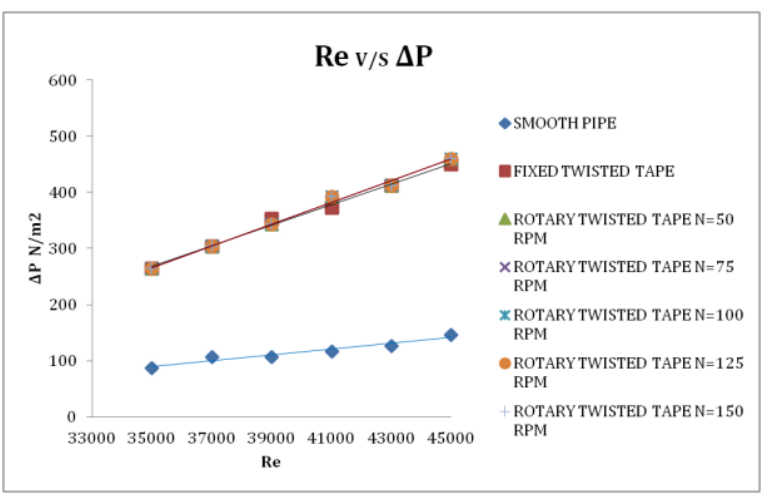

Fig. $10 \mathrm{Re} V / \mathrm{S} \Delta \mathrm{P}$ for fixed twisted tape for $\mathrm{y}=4.0$ and its comparison with smooth pipe

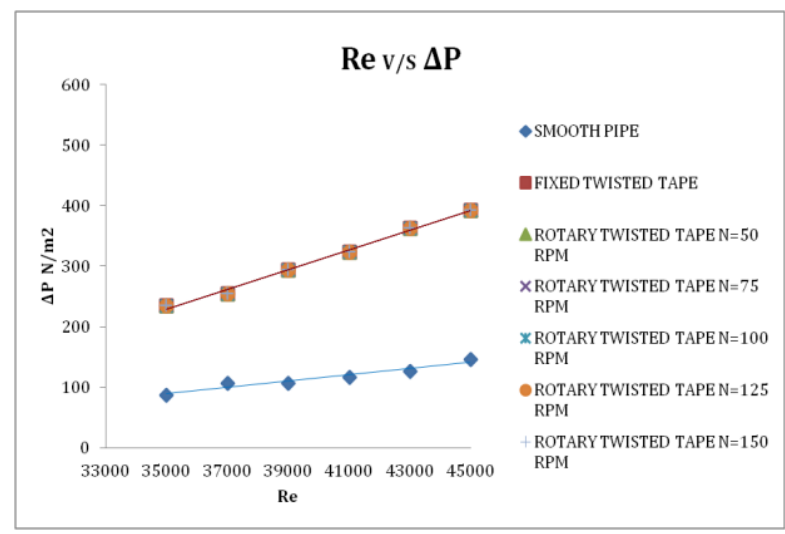

Fig. $11 \operatorname{Re} V / S \Delta P$ for fixed twisted tape for $y=5.0$ and its comparison with smooth pipe

\section{Conclusions}

From the experimental results we can conclude that;

1) Twisted tape inserts increases the heat transfer rate in the heat exchanger by increasing turbulence in the fluid flow.

2) Turbulent flow or swirl flow increases the thermal contact by reducing boundary layer thickness.

3) The turbulent flow ensures the better mixing of the fluid particles which increases heat transfer efficiency.

4) The heat transfer rate increases with decreasing twist ratio and increasing Reynolds number. At small twist ratio and higher RPM the twisted tape 
inserts increases the thermal performance factor around 2.02 times smooth pipe without insert.

5) The twisted tape inserts increases the pressure drop within the pipe and at smaller twist ratios it is maximum.

6) From the experimental results we can conclude that the rotary twisted tape inserts with higher RPM gives higher heat transfer coefficient as compare to smooth pipe without insert.

7) The maximum thermal performance factor obtained in this experimentation was 2.02 times the smooth pipe without inserts at smaller twist ratio $\mathrm{y}=3.0$ and $150 \mathrm{RPM}$.

8) The pressure drop within a pipe with fixed twisted tape insert increases around 4.14 times the smooth pipe without insert at smaller twist ratio $y=3.0$ however, these values does not changes for the rotary twisted tape from 50 to 150RPM.

\section{References}

C.Nithiyesh (April-2012) Kumar, P.Murugesan,'Review On Twisted Tapes Heat Transfer enhancement', International Journal Of Scientific \& Engineering Research, Volume 3, Issue 4.

Anil Singh Yadav (March. 2009) 'Effect of Half Length Twisted-Tape Turbulators on Heat Transfer and Pressure Drop Characteristics inside a Double Pipe U-Bend Heat Exchanger'. Jordan Journal of Mechanical and Industrial Engineering, Volume 3, Number 1, ISSN 1995-6665 Pages 17- 22.
P. Eiamsa-ard, N. Piriyarungroj, C. Thianpong (2014) 'A case study on thermal performance assessment of a heat exchanger tube equipped with regularly-spaced twisted tapes as swirl generators'. Case Studies in Thermal Engineering 3 (2014) 86-102.

Bodius Salam, Sumana Biswas, Shuvra Saha, Muhammad Mostafa K Bhuiya (2013).'Heat transfer enhancement in a tube using rectangular-cut twisted tape insert', Procedia Engineering 56 (2013) $96-103$.

P. Murugesan, K. Mayilsamy, S. Suresh (Dec. 2011) 'Heat Transfer and Friction Factor in a Tube Equipped with U-cut Twisted Tape Insert', Jordan Journal of Mechanical and Industrial Engineering, Volume 5, Number 6, Dec. 2011 ISSN 1995-6665 Pages 559 - 565

M.M.K. Bhuiya, M.S.U. Chowdhury, M. Shahabuddin, M.Sah, L.A.Memon (2013), 'Thermal characteristics in a heat exchanger tube fitted with triple twisted tape inserts', International Communications in Heat and Mass Transfer 48 (2013) 124-132.

Al Amin1, Zunayed Mahmud, Md. Nafis Bin Islam1, Md. Lutfor Rahman and Dr Mohammed Ali (December, 2013),'Heat Transfer Enhancement Using Rotary Twisted Tape Insert' Proceedings of 4th Global Engineering, Science and Technology Conference 27-28 December, 2013, BIAM Foundation, Dhaka, Bangladesh ISBN: 978-1-922069-43-6 